\title{
Inverse Analysis of UHPFRC Beams with a Notch to Evaluate Tensile Behavior
}

\author{
Seong-Cheol Lee, ${ }^{1}$ Han-Byeol Kim, ${ }^{1}$ and Changbin Joh ${ }^{2}$ \\ ${ }^{1}$ Department of NPP Engineering, KEPCO International Nuclear Graduate School, 658-91 Haemaji-ro, Seosaeng-myeon, \\ Ulju-gun, Ulsan 45014, Republic of Korea \\ ${ }^{2}$ Structural Engineering Research Institute, Korea Institute of Civil Engineering and Building Technology (KICT), 283 Goyang-daero, \\ Ilsanseo-gu, Goyang-si, Gyeonggi-do 10223, Republic of Korea
}

Correspondence should be addressed to Seong-Cheol Lee; sclee@kings.ac.kr

Received 1 January 2017; Accepted 20 March 2017; Published 3 April 2017

Academic Editor: Katsuyuki Kida

Copyright (C) 2017 Seong-Cheol Lee et al. This is an open access article distributed under the Creative Commons Attribution License, which permits unrestricted use, distribution, and reproduction in any medium, provided the original work is properly cited.

\begin{abstract}
Recently, ultra high performance fiber reinforced concrete (UHPFRC) has been developed to attain considerably increased compressive cracking strength and ductile tensile behavior with high tensile strength through adding straight steel fibers in concrete mixture. Although benefits with UHPFRC were investigated through experimental program, it is difficult to predict structural behavior of UHPFRC members since theoretical approaches are limited. In this paper, inverse analysis procedure has been proposed for a three-point bending test with notched UHPFRC beams so that tensile behavior of UHPFRC could be rationally evaluated. On the inverse analysis procedure, failure mode of the UHPFRC beam was simplified and the simplified diverse embedment model (SDEM) was employed. To verify the proposed inverse analysis procedure, UHPFRC beams with a notch were analyzed with the tensile behavior of UHPFRC evaluated through the inverse analysis procedure. The analytical predictions showed good agreement with the load-crack mouth opening displacement (CMOD) responses measured through the three-point bending test. Consequently, it can be concluded that UHPFRC tensile behavior can be rationally evaluated through the proposed inverse analysis procedure. The proposed inverse analysis procedure can be useful in relevant research areas such as development of advanced design approaches or computational methods for UHPFRC members.
\end{abstract}

\section{Introduction}

To overcome brittle behavior of concrete after cracking, a number of researches have been conducted to use fiber reinforced concrete as a structural member [1-6]. It is well known that fiber reinforced concrete can exhibit ductile behavior even after cracking because of fibers bridging cracks. Fiber reinforced concrete can be divided into two categories as presented in Figure 1 [7]: conventional fiber reinforced concrete and high performance fiber reinforced concrete (noted as FRC and HPFRC in the figure, resp.). Conventional fiber reinforced concrete usually exhibits softening behavior with a single dominant crack since tensile stress due to fibers is less than cracking strength of concrete matrix. On the other hand, high performance fiber reinforced concrete exhibits stiffening behavior with multiple cracks since tensile stress due to fibers is larger than cracking strength of concrete matrix.
To predict structural behavior of fiber reinforced concrete members, a simple model is required to represent the tensile behavior of fiber reinforced concrete. Through literatures [811], tensile stress attained by fibers was evaluated by considering random distribution of fiber inclination angle and fiber embedment length together. In general, it was fundamentally assumed that bond stress along fibers was uniform. Advanced from the previous models, the diverse embedment model (DEM) $[12,13]$ and the Simplified DEM (SDEM) [14] have been developed with consideration of fiber types such as straight and end-hooked types. Based on the DEM and SDEM, structural behavior of fiber reinforced concrete members with rebars could be more rationally predicted through considering stress distribution in a member and through development of analysis procedure $[15,16]$. Although many models were developed as summarized here, they were primarily focused on fiber reinforced concrete exhibiting 


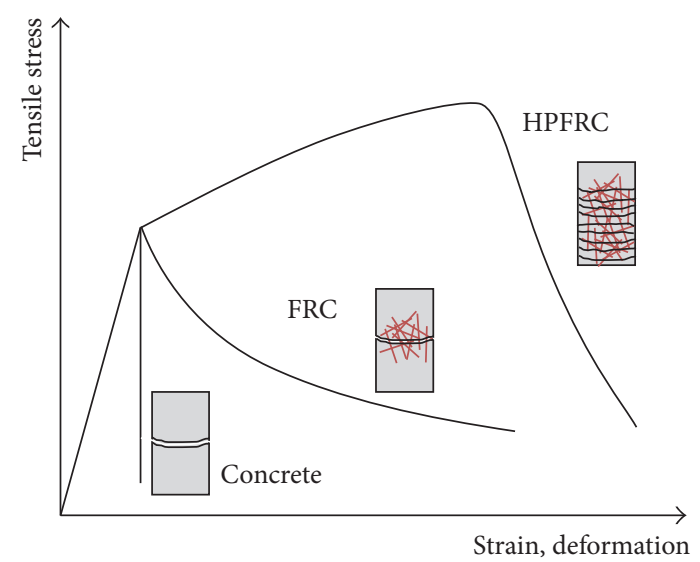

FIGURE 1: Tensile behavior of concrete, FRC, and HPFRC [7].

softening behavior, whereas theoretical models for higher performance fiber reinforced concrete are still limited.

Recently, ultra high performance fiber reinforced concrete (UHPFRC) has been developed, in which coarse aggregate was not included in mixture [17]. UHPFRC can exhibit very high compressive strength more than $150 \mathrm{MPa}$ and ductile tensile behavior with well-distributed multiple cracks. Owning to the characteristics of UHPFRC, it was investigated through experimental programs $[18,19]$ that structural members with UHPFRC exhibited good performance under flexure or shear even with relatively small amount of rebars. Although advantages of UHPFRC were experimentally investigated, theoretical approaches to predict structural behavior of UHPFRC members are very limited.

In this paper, to evaluate tensile behavior of UHPFRC which is one of the most important aspects in analytical predictions for structural behavior, an inverse analysis procedure is proposed so that the tensile behavior of UHPFRC can be rationally evaluated from three-point bending test results with UHPFRC beams which have a notch at the bottom of the mid-point section. To verify the proposed inverse analysis procedure, test results are compared with analytical predictions based on the tensile behavior of UHPFRC evaluated through the proposed inverse analysis procedure.

\section{Inverse Analysis of UHPFRC Beams with a Notch}

2.1. Section Analysis of UHPFRC Beams with a Notch. One of the most important characteristics of UHPFRC is postcrack tensile behavior when structural behavior of members with UHPFRC is theoretically predicted or investigated. On evaluation of tensile behavior of UHPFRC, it is preferred to conduct three-point bending test for a notched beam with a rectangular section as adopted by Yang et al. [18] since the test method is relatively easier than direct tension test with dog-bone shaped specimens [21]. In the case of the bending test, the tensile behavior of UHPFRC can be inferred from test results such as applied load-CMOD (crack mouth opening displacement) response. Recently, CEB-FIP Model Code 2010 (MC10) [22] presented a simple model to evaluate

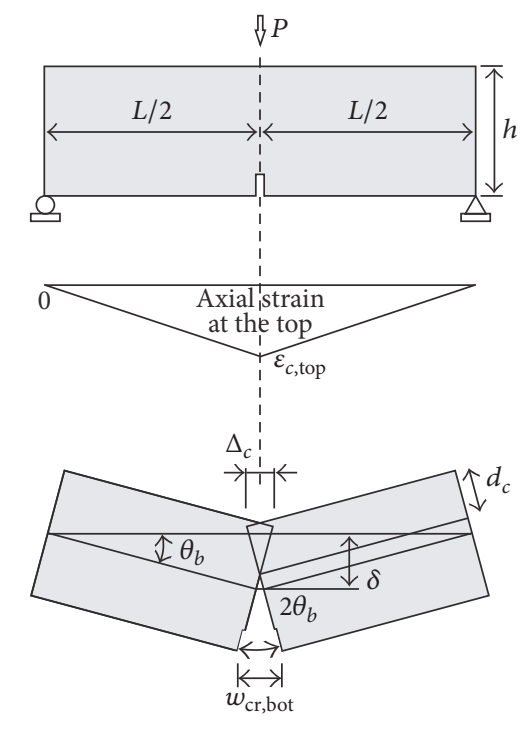

FIGURE 2: Idealized failure mode of UHPFRC beam [20].

tensile stress-crack width response or tensile stress-strain response from the three-point bending test results. However, it was investigated by Lee [20] that effect of fiber type was not rationally considered on the simple model; tensile stress of fiber reinforced concrete with straight fibers could be overestimated while one with end-hooked fibers could be underestimated when crack width is smaller than $1 \mathrm{~mm}$. Therefore, more rational model is required to be developed to represent tensile behavior of UHPFRC.

To derive UHPFRC tension model, inverse analysis has been conducted in this paper, based on section analysis procedure adopted by Lee [20]. It is noted that the section analysis procedure was modified from the analysis method presented by Oh et al. [23] so that effect of a notch at the bottom of the center in a beam can be rigorously taken into the account. As illustrated in Figure 2, UHPFRC beam with a notch was idealized to exhibit a single dominant crack which was developed from a notch. Because a UHPFRC beam specimen subjected to the three-point loading reaches failure through the formation of a single dominant flexural crack and opening of a notch, the failure configuration can be assumed as presented in Figure 2. In this figure, the relationship between the compressive strain, $\varepsilon_{c \text {,top }}$, and the compressive deformation, $\Delta_{c}$, at the top fiber along the section with a notch can be derived as follows:

$$
\Delta_{c}=\int_{0}^{L} \varepsilon_{x, \text { top }} d x=\frac{1}{2} \varepsilon_{c, \text { top }} L,
$$

where $\varepsilon_{x, \text { top }}$ is compressive strain at the top fiber in the section at the distance of $x$ from the support and $L$ is the pure span of the specimen.

From the geometric conditions illustrated in Figure 2, the crack mouth opening displacement at the bottom of a notch (CMOD), $w_{\text {cr,bot }}$, is $2 \theta_{b}\left(h-d_{c}\right)$ where $d_{c}$ is depth to neutral axis from the top fiber. $\theta_{b}$ is rotation angle of cracked beam. From the geometric condition, $\theta_{b}$ can simply be calculated from $\theta_{b}=\Delta_{c} /\left(2 d_{c}\right)$. By incorporating these relationships into 


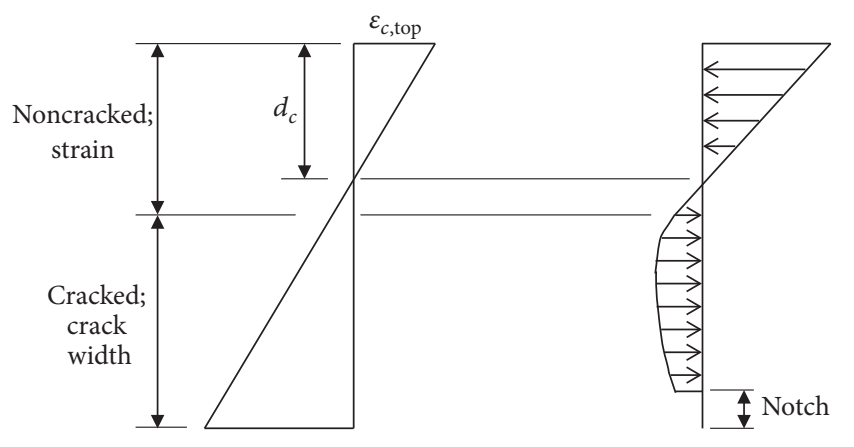

(a)

(b)

FIGURE 3: Crack width, strain, and stress distribution through the section with a notch; (a) section compatibility and (b) stress distribution.

(1), the relationship between $\varepsilon_{c \text {,top }}$ and $w_{\text {cr,bot }}$ can be derived as follows:

$$
\varepsilon_{c, \text { top }}=\frac{2}{L} \frac{d_{c}}{h-d_{c}} w_{\text {cr,bot }} .
$$

With the above equation, the relationship between strain and crack width distributions can be rigorously considered on section compatibility.

2.2. Constitutive Relations for UHPFRC. With the relationship presented in (2), the strain and crack width distribution through the section with a notch can be evaluated as illustrated in Figure 3. Stress distribution along the uncracked depth in the section with a notch can be evaluated for given strain distribution. Since UHPFRC exhibits linear stressstrain response before experiencing the compressive strength [17], the following linear relationship between stress, $f_{c}$, and strain, $\varepsilon_{c}$, in UHPFRC under compression can be employed for the prepeak compressive behavior.

$$
f_{c}=\frac{\varepsilon_{c}}{\varepsilon_{\mathrm{co}}} f_{c}^{\prime}=\varepsilon_{c} E_{c} \quad \text { for } \varepsilon_{\mathrm{co}} \leq \varepsilon_{c}<0,
$$

where $f_{c}^{\prime}$ is the compressive strength of UHPFRC, $\varepsilon_{\mathrm{co}}$ is strain corresponding to $f_{c}^{\prime}$, and $E_{c}$ is the elastic modulus of UHPFRC.

As a similar way, the tensile behavior in UHPFRC before cracking can be expressed as follows:

$$
f_{c}=\varepsilon_{c} E_{c} \quad \text { for } 0 \leq \varepsilon_{c}<\varepsilon_{\mathrm{cr}},
$$

where $\varepsilon_{\mathrm{cr}}=f_{\mathrm{cr}} / E_{c}$ and $f_{\mathrm{cr}}$ is cracking strength of concrete matrix which can be assumed to be $0.5 \sqrt{f_{c}^{\prime}}$ when it is not provided from the test.

Along the cracked depth above the notch in the section, tensile stress of UHPFRC can be calculated as sum of tensile stresses due to tension-softening effect of concrete matrix and straight fibers $\left(f_{\mathrm{ct}}\right.$ and $f_{f}$, resp. $)$ as follows:

$$
f_{c}=f_{\mathrm{ct}}+f_{f}
$$

The tensile stress due to the tension-softening effect of concrete matrix can be evaluated as follows [9]:

$$
f_{\mathrm{ct}}=f_{\mathrm{cr}} e^{-c w_{\mathrm{cr}}},
$$

where the coefficient $c$ is 30 for UHPFRC since there is no coarse aggregate in UHPFRC.

The tensile stress of UHPFRC can be evaluated for a given crack width which is calculated from (2). From the SDEM [14], which was simplified from the diverse embedment model (DEM) $[12,13]$, tensile stress due to straight steel fibers can be calculated for a given crack width, $w_{\mathrm{cr}}$, as follows:

$$
f_{f}=\alpha_{f} V_{f} K_{\mathrm{st}} \tau_{f, \max } \frac{l_{f}}{d_{f}}\left(1-\frac{2 w_{\mathrm{cr}}}{l_{f}}\right)^{2},
$$

where $\alpha_{f}$ is fiber orientation factor, usually can be taken to be $0.5, V_{f}$ is fiber volumetric ratio, $\tau_{f \text {, max }}$ is pullout strength of a straight steel fiber, $l_{f}$ is fiber length, $d_{f}$ is fiber diameter, and $K_{\mathrm{st}}$ is a factor to represent average pullout stress of fibers considering random distribution of fibers. $K_{\text {st }}$ can be calculated for a given crack width from the following:

$$
K_{\mathrm{st}}= \begin{cases}\frac{\beta_{f}}{3} \frac{w_{\mathrm{cr}}}{s_{f}}, & \text { for } w_{\mathrm{cr}}<s_{f}, \\ 1-\sqrt{\frac{s_{f}}{w_{\mathrm{cr}}}}+\frac{\beta_{f}}{3} \sqrt{\frac{s_{f}}{w_{\mathrm{cr}}}}, & \text { for } w_{\mathrm{cr}} \geq s_{f},\end{cases}
$$

where $\beta_{f}$ is a coefficient to consider effect of fiber slip, which is 0.67 , and $s_{f}$ is the fiber slip corresponding to the pullout strength of a straight steel fiber, which can be taken to be $0.01 \mathrm{~mm}$.

2.3. Analysis Algorithm for the Inverse Analysis. Among the parameters required to conduct section analysis, only the pullout strength of straight steel fiber, $\tau_{f \text {, max }}$, is an unknown variable. At the beginning of the inverse analysis, therefore, $\tau_{f, \max }$ is assumed, then the section analysis for the section with a notch can be conducted through an iteration procedure, finding the neutral axis depth for a given crack mouth opening displacement at the bottom of the notch by satisfying force equilibrium along the longitudinal axis. On the section analysis, strain and crack width distribution along the section can be evaluated from (2) for a given $w_{\text {cr,bot }}$; then stress distribution along the section can be evaluated from (3) (8). From the stress distribution, the sectional moment, $M$, can be calculated for the section with a notch. Finally, the applied load, $P$, for a given crack mouth opening displacement can be calculated as follows:

$$
P=\frac{4 M}{L}
$$

Consequently, with an initially assumed pullout strength of a straight steel fiber, $\tau_{f \text {,max }}$, the applied load-crack mouth opening displacement response of UHPFRC beam with a notch can be evaluated through the section analysis with variation of crack mouth opening displacement. Then, through comparing the maximum applied force, $P_{\max }$, with test result, 


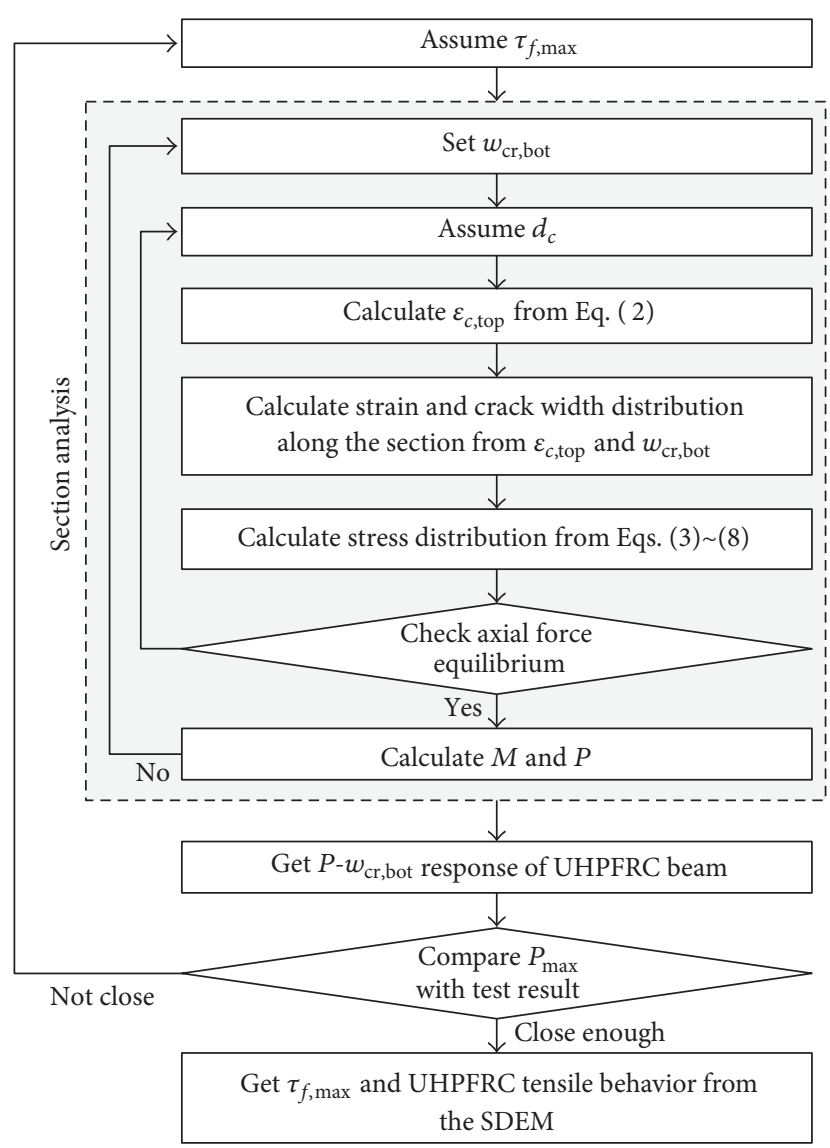

FIgURE 4: Analysis algorithm for the inverse analysis.

the pullout strength of a straight steel fiber, $\tau_{f \text {, max }}$, can be evaluated. Now the tensile stress-crack width response of UHPFRC can be evaluated from the SDEM, which has been presented with (5) (8).

Details about the inverse analysis algorithm have been presented in Figure 4.

\section{Verification of the Proposed Inverse Analysis Procedure}

3.1. Subject Members and Materials. In this paper, UHPFRC specimens tested by Yang et al. [18] have been considered for verification of the proposed inverse analysis procedure. In their study, a series of UHPFRC beams with a notch was fabricated and tested. In the experimental program, the threepoint bending test was conducted to investigate the tensile behavior of UHPFRC.

Figure 5 shows details about the UHPFRC beams. As illustrated in the figure, the UHPFRC beams had a height of $100 \mathrm{~mm}$, a width of $100 \mathrm{~mm}$, a pure span of $300 \mathrm{~mm}$, and a length of $400 \mathrm{~mm}$. Each specimen had a notch with a depth of $10 \mathrm{~mm}$ which was placed at the bottom of the mid-section in the pure span. During the three-point bending test, the crack mouth opening displacement was measured through a clip gauge attached to the bottom face of the specimen on either side of the notch.

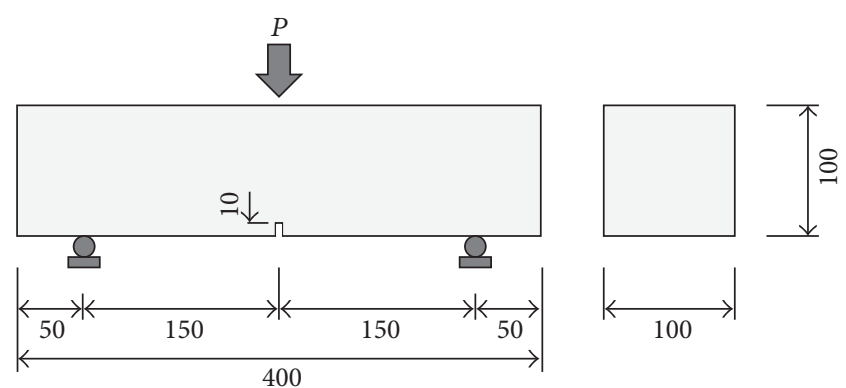

FIGURE 5: Details about the three-point bending test for UHPFRC [18].

TABLE 1: Mix proportion of UHPFRC by weight ratio [18].

\begin{tabular}{|c|c|c|c|c|c|c|}
\hline $\mathrm{W} / \mathrm{B}$ & Cement & $\begin{array}{l}\text { Silica } \\
\text { fume }\end{array}$ & Filler & $\begin{array}{c}\text { Fine } \\
\text { aggregate }\end{array}$ & $\begin{array}{c}\text { Water- } \\
\text { reducing } \\
\text { admixture }\end{array}$ & $\begin{array}{c}\text { Steel fiber } \\
\text { volumetric } \\
\text { ratio, } \%\end{array}$ \\
\hline 0.2 & 1.0 & 0.25 & 0.3 & 1.1 & 0.02 & $1.0,1.5,2.0$ \\
\hline
\end{tabular}

In Table 1, mix proportion of UHPFRC has been presented. As presented in the table, no coarse aggregates were provided while fine aggregates consisting of sands with diameters of less than $0.5 \mathrm{~mm}$ were added. The water-binder ratio $(\mathrm{W} / \mathrm{B})$ was 0.2 so that high compressive strength could be achieved. To attain postcrack ductile behavior, straight steel fibers were provided, which have a diameter of $0.2 \mathrm{~mm}$, a length of $13 \mathrm{~mm}$, and yield strength of 2,500 MPa. Test variable was fiber volumetric ratio, which was varied through $1.0,1.5$, and $2.0 \%$.

Representative material properties of UHPFRC have been presented in Table 2, including compressive strength and elastic modulus. The notation for the specimens means test parameters which are shear span-to-depth ratio (S25 and S34 for 2.5 and 3.4, resp.), fiber volumetric ratio (F10, F15, and F20 for fiber volumetric ratio of $1.0,1.5$, and $2.0 \%$, resp.), and presence or absence of prestress ( $\mathrm{P} 0$ and PS for presence and absence of prestress, resp.). As presented in the table, the compressive strength and elastic modulus were much higher than normal concrete without fibers: 167.2 193.0 MPa for the compressive strength and $43,400 \sim 47,780 \mathrm{MPa}$ for the elastic modulus. It is noted that UHPFRC exhibited almost linear stress-strain response before experiencing the compressive strength since no coarse aggregate was provided. In the table, the maximums on the applied load, $P_{\max }$, measured through the three-point bending test have been also presented. It is noted that $P_{\max }$ in the table was calculated through average of $3 \sim 6$ test results for each test group.

3.2. Evaluation of the Tensile Behavior of UHPFRC. In order to evaluate the tensile behavior of UHPFRC, the pullout strength of a straight steel fiber has been evaluated through the proposed inverse analysis with the SDEM. When the pullout strength was evaluated, the maximum applied load, $P_{\max }$, measured through the three-point bending test was compared with ones predicted by the inverse analysis, the pullout strength to get the maximum load predicted by the 
TABLE 2: Material properties of UHPFRC and the maximum load from the three-point bending test [18].

\begin{tabular}{|c|c|c|c|c|}
\hline Specimen & Compressive strength, $\mathrm{MPa}$ & Elastic modulus, $\mathrm{MPa}$ & $\begin{array}{c}\text { Fiber volumetric } \\
\text { ratio, } \%\end{array}$ & $P_{\max }$ from the test, $\mathrm{kN}$ \\
\hline S25-F10-P0 & 174.5 & 43,550 & 1.0 & 48.4 \\
\hline S25-F10-PS & 181.3 & 45,560 & 1.0 & 44.0 \\
\hline S25-F15-P0 & 188.2 & 45,930 & 1.5 & 63.8 \\
\hline S25-F15-PS & 183.6 & 45,850 & 1.5 & 64.8 \\
\hline $\mathrm{S} 25-\mathrm{F} 20-\mathrm{P} 0$ & 185.5 & 47,780 & 2.0 & 71.4 \\
\hline S25-F20-PS & 189.8 & 45,510 & 2.0 & 77.7 \\
\hline S34-F10-P0 & 168.9 & 43,400 & 1.0 & 47.0 \\
\hline S34-F10-PS & 167.2 & 44,050 & 1.0 & 42.3 \\
\hline S34-F15-P0 & 193.0 & 46,920 & 1.5 & 64.8 \\
\hline S34-F15-PS & 189.2 & 45,280 & 1.55 & 66.9 \\
\hline S34-F20-P0 & 188.5 & 46,290 & 2.0 & 74.3 \\
\hline S34-F20-PS & 182.3 & 45,350 & 2.0 & 73.5 \\
\hline
\end{tabular}

TABLE 3: Pullout strength of a fiber in UHPFRC evaluated through the inverse analysis.

\begin{tabular}{lc}
\hline Specimen & Pullout strength, MPa \\
\hline S25-F10-P0 & 44.9 \\
S25-F10-PS & 40.4 \\
S25-F15-P0 & 40.5 \\
S25-F15-PS & 41.0 \\
S25-F20-P0 & 34.1 \\
S25-F20-PS & 37.9 \\
S34-F10-P0 & 43.5 \\
S34-F10-PS & 38.8 \\
S34-F15-P0 & 41.0 \\
S34-F15-PS & 42.6 \\
S34-F20-P0 & 35.9 \\
S34-F20-PS & 35.6 \\
\hline
\end{tabular}

inverse analysis close enough to the test result. Table 3 shows the pullout strengths evaluated through the proposed inverse analysis. As presented in the table, the pullout strengths were evaluated to be 34.1 44.9 which were much higher than the suggestions by Voo and Foster [9] in which pullout strength of a straight steel fiber was assumed to be 1.0 times of matrix tensile strength in specimens with no coarse aggregate. Since UHPFRC mix proportion is quite different from conventional concrete or mortar, it can be inferred that provisions designated for conventional concrete cannot be employed to evaluate the pullout strength of a fiber in UHPFRC. In addition, it was investigated that the evaluated pullout strength for specimens with $2.0 \%$ of fiber volumetric ratio was less than ones with 1.0 or $1.5 \%$ of fiber volumetric ratio. This result is compatible with the test results observed by Lee et al. [21]; fiber efficiency generally decreased as fiber volumetric ratio increased. This indicates that the pullout strength of a fiber is affected not only by fibers and concrete mixture but also by fiber volumetric ratio, specifically when fiber volumetric ratio is larger than $1.5 \%$.
From the evaluated pullout strengths of a straight steel fiber in UHPFRC, the tensile behaviors of UHPFRC were evaluated, based on the SDEM which has been expressed with (5) (8). The evaluated tensile stress-crack width responses of UHPFRC have been presented in Figure 6. As a similar way to the pullout strength of a straight steel fiber in UHPFRC, the tensile stress of UHPFRC did not proportionally increase with an increase of fiber volumetric ratio. In addition, as can be seen in the figures, it was evaluated that the maximum tensile stress of UHPFRC was larger than cracking strength. Therefore, it can be inferred that UHPFRC may exhibit postcrack strain-hardening behavior with distributed multiple cracks.

3.3. Comparison with the Three-Point Bending Test Results. To verify the proposed inverse analysis procedure, the section analysis presented with the gray box with dotted lines in Figure 4 was conducted for the section with a notch, and the test results were compared with the tensile stress-CMOD response predicted by the section analysis in Figure 7 . It should be noted that the UHPFRC tensile behavior in Figure 6 was employed on the section analysis. As can be seen in the figure, the tensile stress-CMOD response predicted by the section analysis showed good agreement with the test results. In the comparisons, the test results were scattered from the predictions, but this is mainly caused by the nature of fiber reinforced concrete; fiber reinforced concrete exhibits relatively considerable scattering tensile behavior because of random distribution of fibers [21, 24, 25].

Figure 8 shows an example for stress distribution along the section with a notch. It is noted that the maximum applied loads corresponded to the CMOD around $1.0 \mathrm{~mm}$ in the specimens, S25-F10-P0 and S25-F20-P0. As presented in the figure, stress along cracked region decreases with increasing the opening displacement. In addition, since S25-F10-P0 and S25-F20-P0 had the cracking strengths of 6.60 and $6.81 \mathrm{MPa}$, respectively, it is obvious that maximum tensile stress of UHPFRC was larger than cracking strength. These results are compatible with the SDEM and the proposed method in this paper. 

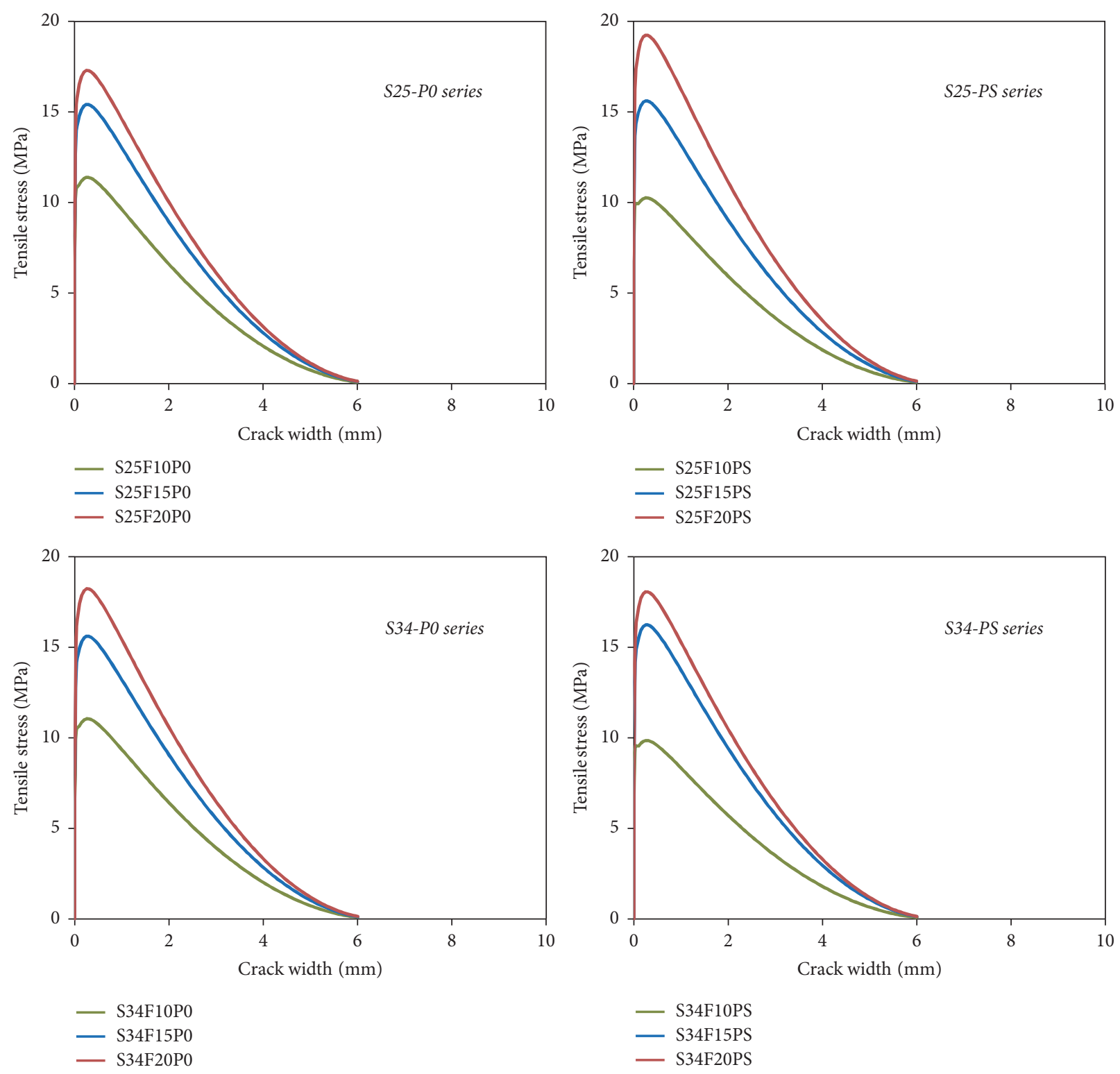

FIGURE 6: Tensile behavior of UHPFRC evaluated through the proposed inverse analysis with the SDEM.

Consequently, it can be concluded that the tensile behavior of UHPFRC can be reasonably predicted by the pullout strength which is evaluated through the proposed inverse analysis based on the section analysis with the SDEM.

\section{Conclusion}

In this paper, an inverse analysis procedure has been proposed to evaluate tensile behavior of UHPFRC from test results with notched UHPFRC beams subjected to threepoint flexural loading. The proposed inverse analysis procedure is based on section analysis in which the SDEM is employed to take into account UHPFRC stress distribution along the section with a notch. Since pullout strength of a straight fiber can be directly evaluated from the maximum load measured through the three-point bending test, tensile behavior of UHPFRC can be easily predicted with the SDEM.
To verify the proposed inverse analysis procedure, UHPFRC beams with a notch subjected to three-point flexural loading have been analyzed with the tensile behavior of UHPFRC evaluated through the proposed inverse analysis procedure. The analysis results showed good agreement with the test results expressed to the applied load-CMOD response. It can be concluded that the tensile behavior of UHPFRC can be reasonably evaluated from the proposed inverse analysis procedure.

The proposed inverse analysis procedure can be useful in evaluating tensile behavior of concrete with other types of fibers like end-hooked fibers, crimped fibers, and so on. In addition, through simplification of the proposed inverse analysis procedure, it is anticipated that this paper can be useful in developing advanced design approaches or more rational computational methods for UHPFRC members. 

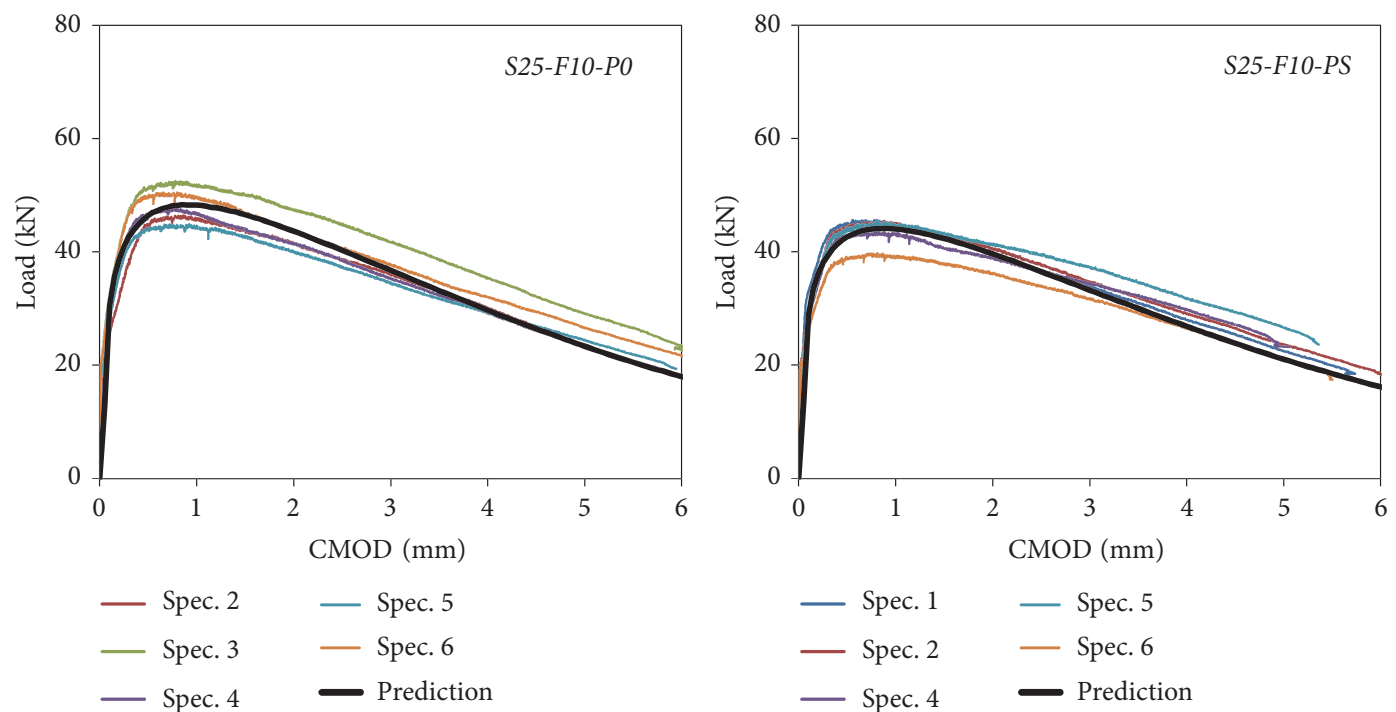

- Spec. 1 - Spec. 5

- Spec. 2 - Spec. 6

- Spec. 4 Prediction
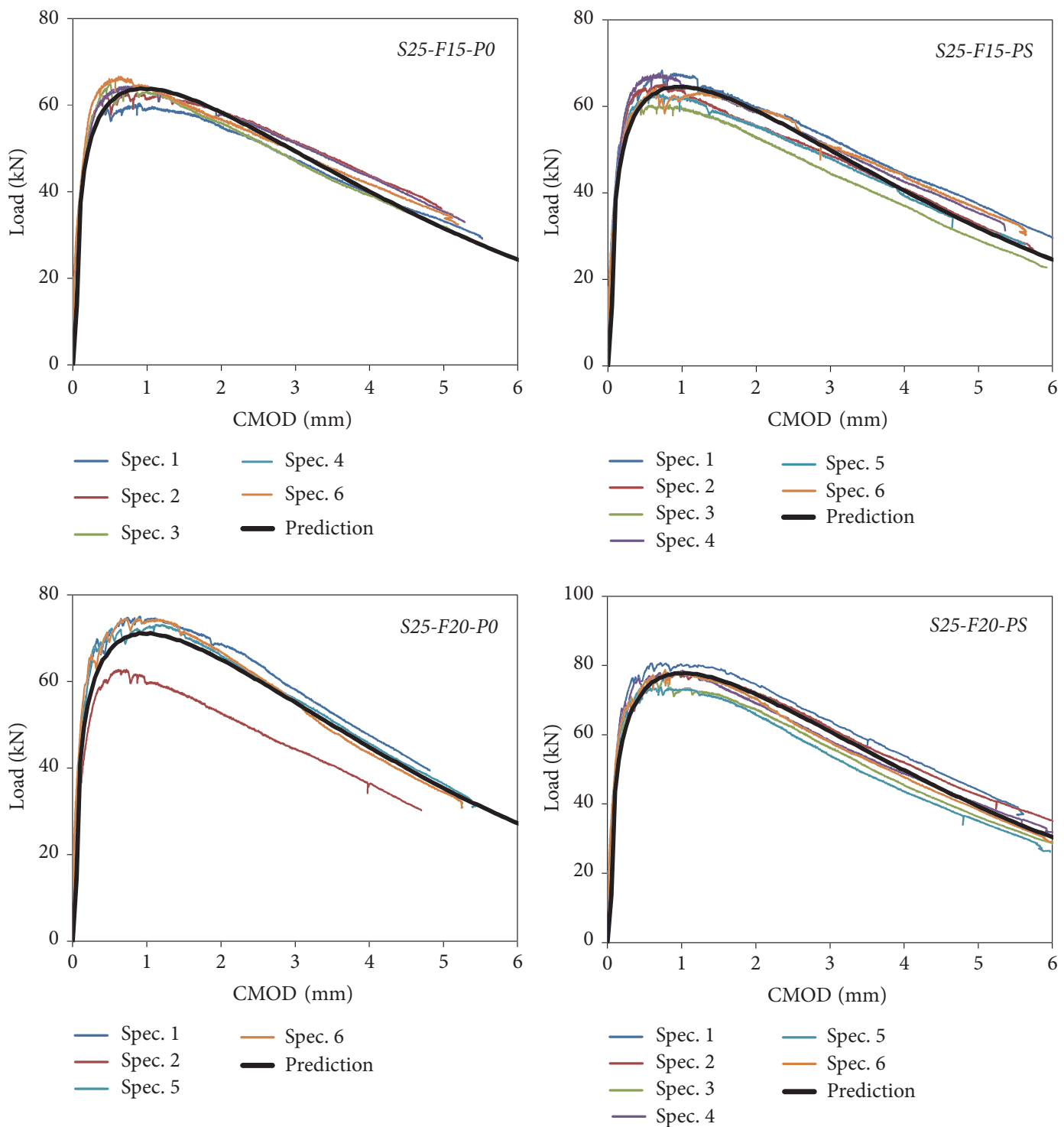

Figure 7: Continued. 

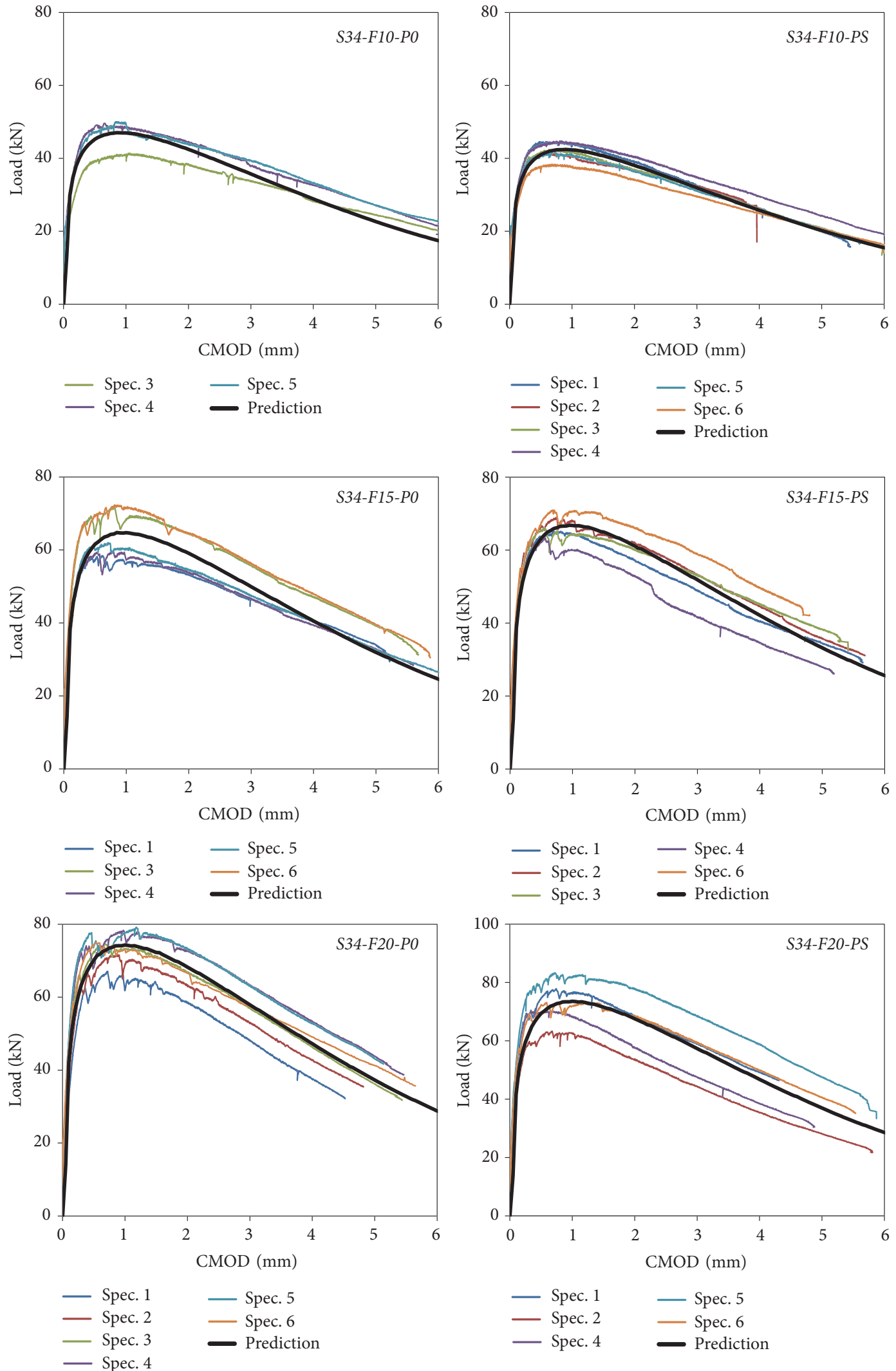

FIGURE 7: Comparison on the applied load-CMOD response. 

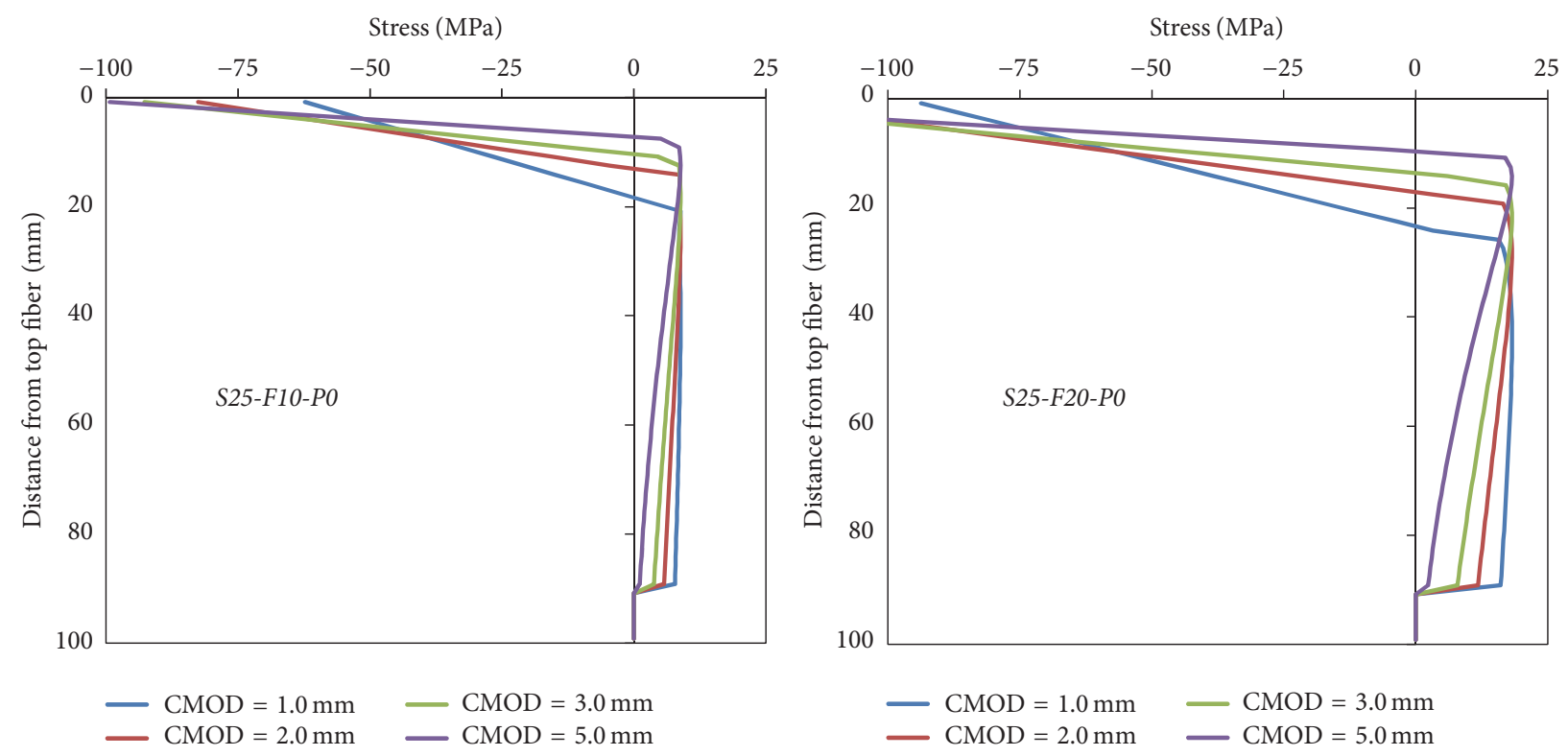

FIGURE 8: Stress distribution along the section with a notch.

\section{Conflicts of Interest}

The authors declare that there are no conflicts of interest regarding the publication of this paper.

\section{Acknowledgments}

This research was supported by a grant (13SCIPA02) from Smart Civil Infrastructure Research Program funded by Ministry of Land, Infrastructure and Transport (MOLIT) of Korea government and Korea Agency for Infrastructure Technology Advancement (KAIA).

\section{References}

[1] P. H. Bischoff, "Tension stiffening and cracking of steel fiberreinforced concrete," Journal of Materials in Civil Engineering, vol. 15, no. 2, pp. 174-182, 2003.

[2] B. Bae, H. Choi, B. Lee, and C. Bang, "Compressive behavior and mechanical characteristics and their application to stress-strain relationship of steel fiber-reinforced reactive powder concrete," Advances in Materials Science and Engineering, vol. 2016, Article ID 6465218, 11 pages, 2016.

[3] H. H. Dinh, G. J. Parra-Montesinos, and J. K. Wight, "Shear behavior of steel fiber-reinforced concrete beams without stirrup reinforcement," ACI Structural Journal, vol. 107, no. 5, pp. 597-606, 2010.

[4] J. Susetyo, P. Gauvreau, and F. J. Vecchio, "Effectiveness of steel fiber as minimum shear reinforcement," ACI Structural Journal, vol. 108, no. 4, pp. 488-496, 2011.

[5] M. H. Harajli and A. A. Rteil, "Effect of confinement using fiberreinforced polymer or fiber-reinforced concrete on seismic performance of gravity load-designed columns," ACI Structural Journal, vol. 101, no. 1, pp. 47-56, 2004.

[6] Y. ChiaHwan and H. JianBo, "The mechanical behavior of fiber reinforced PP ECC beams under reverse cyclic loading,"
Advances in Materials Science and Engineering, vol. 2014, Article ID 159790, 9 pages, 2014.

[7] A. E. Naaman and H. W. Reinhardt, "Characterization of high performance fiber reinforced cement composites-HPFRCC," in Proceedings of HPFRCC 2, pp. 1-23, 1995.

[8] P. Marti, T. Pfyl, V. Sigrist, and T. Ulaga, "Harmonized test procedures for steel fiber-reinforced concrete," ACI Materials Journal, vol. 96, no. 6, pp. 676-685, 1999.

[9] J. Y. L. Voo and S. J. Foster, "Variable engagement model for fibre reinforced concrete in tension," UNICIV Report R-420, School of Civil and Environmental Engineering, the University of New South Wales, Sydney, Australia, 2003.

[10] T. Leutbecher and E. Fehling, "Crack width control for combined reinforcement of rebars and fibers exemplified by ultrahigh-performance concrete," fib Task Group 8.6, Ultra High Performance Fiber Reinforced Concrete-UHPFRC, pp. 1-28, 2008.

[11] P. Stroeven, "Stereological principles of spatial modeling applied to steel fiber-reinforced concrete in tension," ACI Materials Journal, vol. 106, no. 3, pp. 213-222, 2009.

[12] S.-C. Lee, J.-Y. Cho, and F. J. Vecchio, "Diverse embedment model for steel fiber-reinforced concrete in tension: model development," ACI Materials Journal, vol. 108, no. 5, pp. 516$525,2011$.

[13] S.-C. Lee, J.-Y. Cho, and F. J. Vecchio, "Diverse embedment model for steel fiber-reinforced concrete in tension: model verification," ACI Materials Journal, vol. 108, no. 5, pp. 526-535, 2011.

[14] S.-C. Lee, J.-Y. Cho, and F. J. Vecchio, "Simplified diverse embedment model for steel fiber-reinforced concrete elements in tension," ACI Materials Journal, vol. 110, no. 4, pp. 403-412, 2013.

[15] S.-C. Lee, J.-Y. Cho, and F. J. Vecchio, “Tension-stiffening model for steel fiber-reinforced concrete containing conventional reinforcement," ACI Structural Journal, vol. 110, no. 4, pp. 639-648, 2013. 
[16] S.-C. Lee, J.-Y. Cho, and F. J. Vecchio, "Analysis of steel fiberreinforced concrete elements subjected to shear," ACI Structural Journal, vol. 113, no. 2, pp. 275-285, 2016.

[17] K. Kim, I. Yang, and C. Joh, "Material properties and structural characteristics on flexure of steel fiber-reinforced ultra-highperformance concrete," Journal of the Korea Concrete Institute, vol. 28, no. 2, pp. 177-185, 2016.

[18] I.-H. Yang, C. Joh, and B.-S. Kim, "Shear behaviour of ultrahighperformance fibre-reinforced concrete beams without stirrups," Magazine of Concrete Research, vol. 64, no. 11, pp. 979993, 2012.

[19] I. H. Yang, C. Joh, and B.-S. Kim, "Structural behavior of ultra high performance concrete beams subjected to bending," Engineering Structures, vol. 32, no. 11, pp. 3478-3487, 2010.

[20] S.-C. Lee, "Re-evaluation of fibre-reinforced concrete tension model in CEB-FIP Model Code 2010," Materials Research Innovations, vol. 19, supplement 8, pp. 107-110, 2015.

[21] S.-C. Lee, J.-H. Oh, and J.-Y. Cho, "Fiber efficiency in SFRC members subjected to uniaxial tension," Construction and Building Materials, vol. 113, pp. 479-487, 2016.

[22] International Federation for Structural Concrete (fib), fib Model Code for Concrete Structures 2010, Ernst \& Sohn, 2013.

[23] B. H. Oh, D. G. Park, J. C. Kim, and Y. C. Choi, "Experimental and theoretical investigation on the postcracking inelastic behavior of synthetic fiber reinforced concrete beams," Cement and Concrete Research, vol. 35, no. 2, pp. 384-392, 2005.

[24] S.-C. Lee, J.-H. Oh, and J.-Y. Cho, "Fiber orientation factor on a circular cross-section in concrete members," Journal of the Korea Concrete Institute, vol. 26, no. 3, pp. 307-313, 2014.

[25] S.-C. Lee, J.-H. Oh, and J.-Y. Cho, "Fiber orientation factor on rectangular cross-section in concrete members," International Journal of Engineering and Technology, vol. 7, no. 6, pp. 470-473, 2015. 

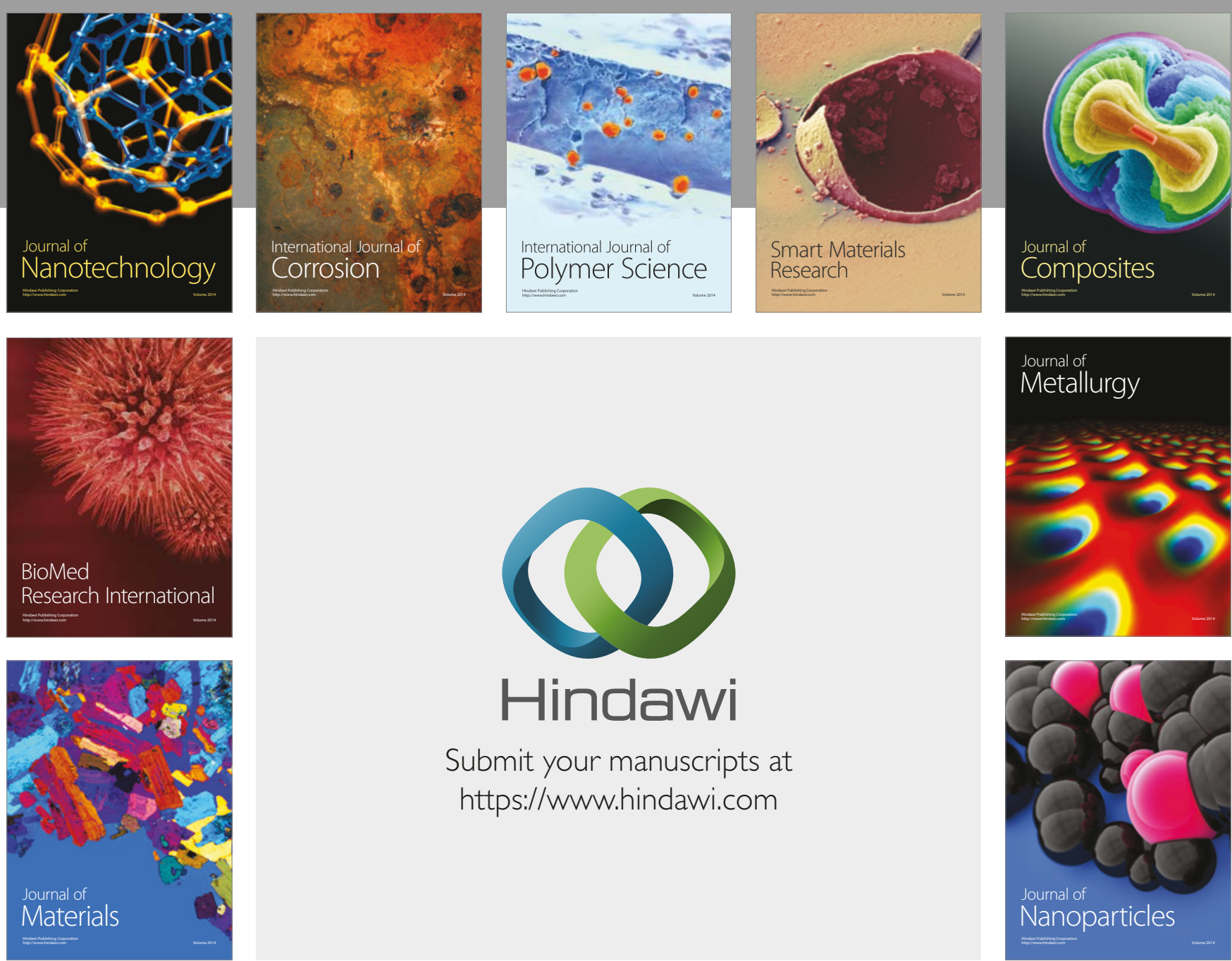

\section{Hindawi}

Submit your manuscripts at

https://www.hindawi.com
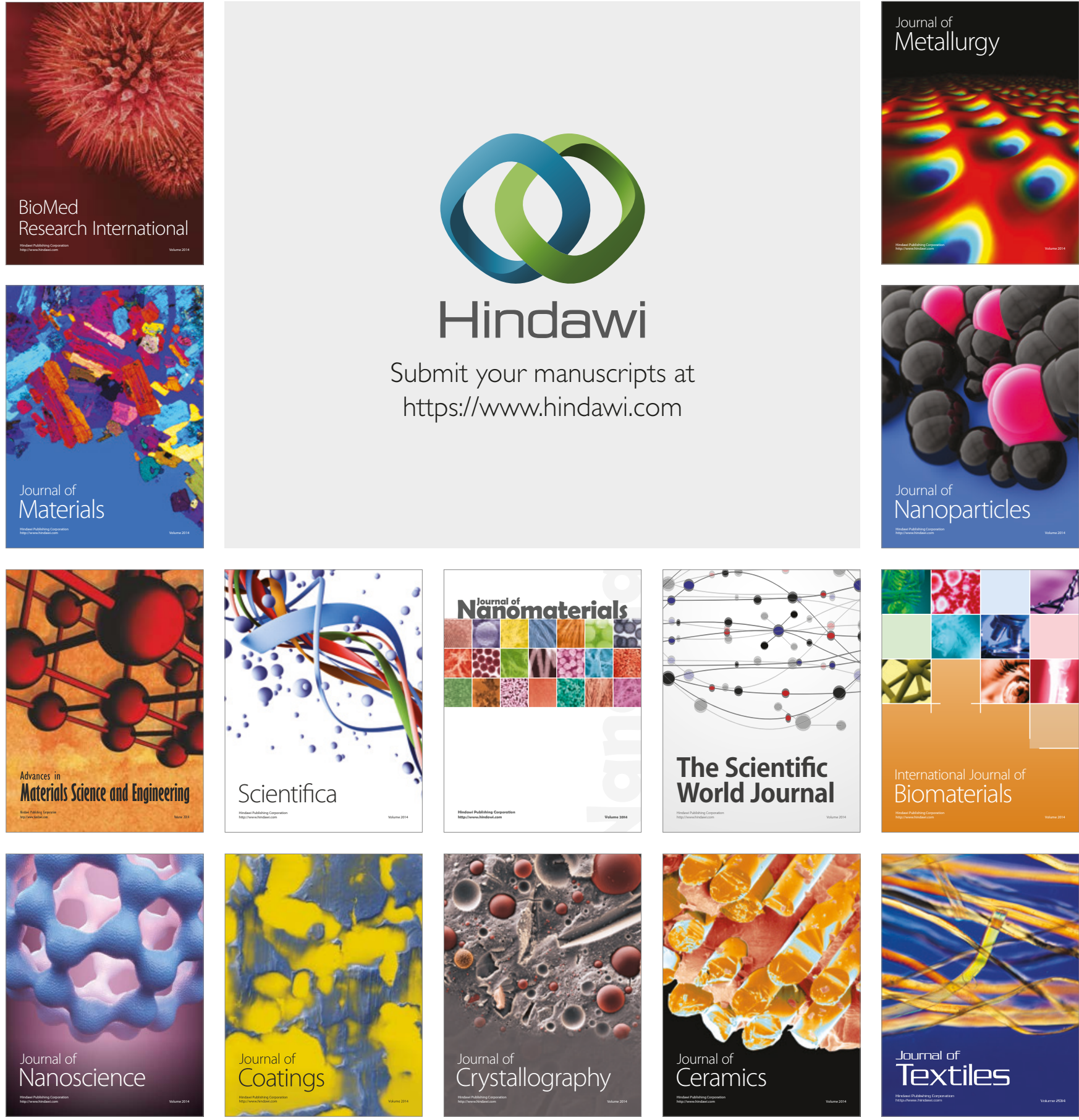

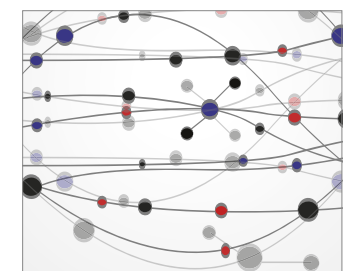

The Scientific World Journal
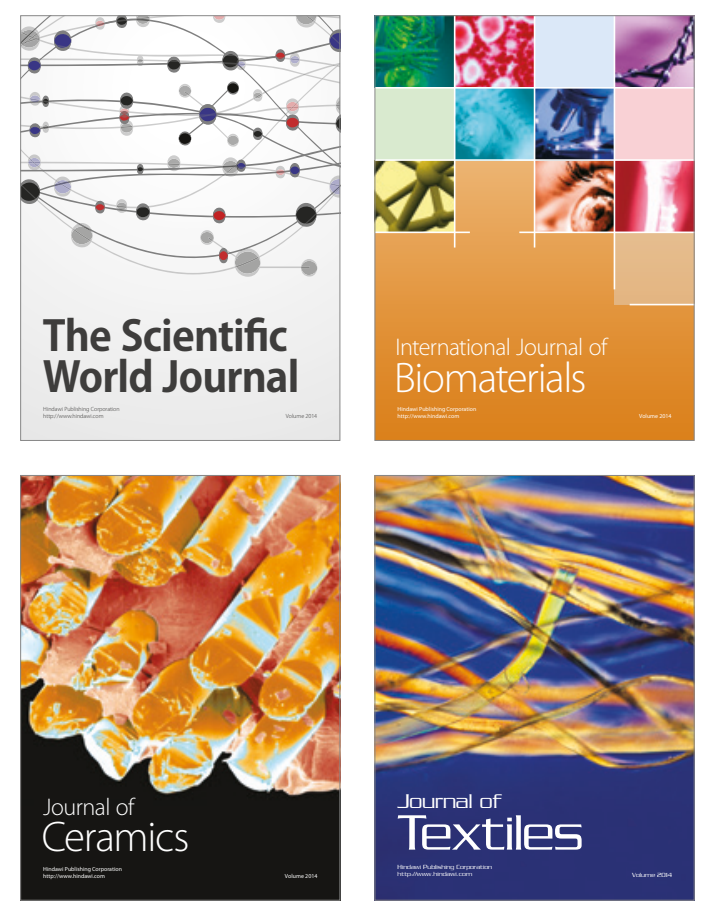